\title{
BMJ Open Accidental hypothermia in Denmark: A nationwide cohort study of incidence and outcomes
}

\author{
Sebastian Wiberg (D) , ${ }^{1}$ Asmus Friborg Mortensen, ${ }^{2}$ Jesper Kjaergaard, ${ }^{1}$ \\ Christian Hassager, ${ }^{1,3}$ Michael Wanscher ${ }^{4}$
}

To cite: Wiberg S,

Mortensen AF, Kjaergaard J, et al. Accidental hypothermia in Denmark: A nationwide cohort study of incidence and outcomes. BMJ Open 2021;11:e046806. doi:10.1136/ bmjopen-2020-046806

- Prepublication history for this paper is available online. To view these files, please visit the journal online (http://dx.doi. org/10.1136/bmjopen-2020046806).

SW and AFM contributed equally.

Received 09 November 2020 Accepted 14 May 2021

Check for updates

(C) Author(s) (or their employer(s)) 2021. Re-use permitted under CC BY-NC. No commercial re-use. See rights and permissions. Published by BMJ.

${ }^{1}$ Department of Cardiology, Rigshospitalet, Copenhagen, Denmark

${ }^{2}$ Department of Anaesthesiology and Intensive Care, Bispebjerg and Frederiksberg Hospital, Copenhagen, Denmark

${ }^{3}$ Department of Clinical

Medicine, University of

Copenhagen, Copenhagen,

Denmark

${ }^{4}$ Department of CardioThoracic Anaesthesiology, Rigshospitalet, Copenhagen, Denmark

Correspondence to Dr Sebastian Wiberg; Sebastian.christoph.wiberg@ regionh.dk

\section{ABSTRACT}

Objectives To investigate the incidence of accidental hypothermia $(\mathrm{AH})$ in a nationwide registry and the associated outcomes.

Design Nationwide retrospective cohort study Participants and settings All patients at least 18 years old, admitted to hospitals in Denmark with a diagnosis of $\mathrm{AH}$, with an International Classification of Diseases, 10th edition code of T689, from January 1996 to November 2016. Other recorded diagnoses were included in the analyses.

Primary and secondary outcome measures The primary outcome was 1-year mortality.

Results During the inclusion period, 5242 patients were admitted with a diagnosis of $\mathrm{AH}$, corresponding to a mean annual incidence of $4.4 \pm 1.2$ (range by calendar year: 2.9 6.4) per 100000 inhabitants. A total of $2230(43 \%)$ had $\mathrm{AH}$ recorded as the primary diagnosis without any recorded secondary diagnoses (primary $\mathrm{AH}), 1336(25 \%)$ had $\mathrm{AH}$ recorded as the primary diagnosis with other recorded secondary diagnoses ( $\mathrm{AH}+2^{\circ}$ diagnosis), and 1676 (32\%) had $\mathrm{AH}$ recorded as a secondary diagnosis with another recorded primary diagnosis ( $1^{\circ}$ diagnosis $\left.+\mathrm{AH}\right)$. Alcohol intoxication was the most common diagnosis associated with AH. Overall 1-year mortality was $27 \%$. In patients with primary $\mathrm{AH}, 1$-year mortality was $22 \%$, compared with $26 \%$ in patients with secondary $\mathrm{AH}$ type I, and $35 \%$ in patients with secondary AH type II $\left(\mathrm{p}_{\text {log-rank }}<0.001\right)$.

Conclusions The present study investigated the incidence of $\mathrm{AH}$, associated comorbidities and mortality after $\mathrm{AH}$ in Denmark from 1995 to 2016 . The diagnosis is associated with a high comorbidity burden and a considerable 1year mortality. In the high proportion of patients with associated comorbidities, establishing whether $\mathrm{AH}$ or the comorbidities are the drivers of mortality remains difficult. This complicates our understanding of $\mathrm{AH}$ and makes it difficult to find modifiable factors associated with both $\mathrm{AH}$ and outcomes. Future prospective studies are needed elucidate the causal relationship between $\mathrm{AH}$ and associated comorbidities.

\section{INTRODUCTION}

Accidental hypothermia (AH), defined as an involuntary drop in core temperature below $35^{\circ} \mathrm{C}$, is a serious condition with considerable mortality. ${ }^{12} \mathrm{AH}$ can result from isolated cold exposure (primary hypothermia) or

\section{Strengths and limitations of this study}

Large contemporary study to investigate the incidence, comorbidity burden and outcome in patients diagnosed with accidental hypothermia.

- Data originated from a national cohort of patients.

- The registry data limited the data granularity to what has been presented in the present paper.

- The presented incidences are likely to be significantly different in other countries, depending on climate, demography and so on.

in association with acute or chronic illness (secondary hypothermia). ${ }^{2}$ The severity of hypothermia can be graded into three stages based on core temperature: $32^{\circ} \mathrm{C}-35^{\circ} \mathrm{C}$ (mild $\mathrm{AH}), 28^{\circ} \mathrm{C}-32^{\circ} \mathrm{C}$ (moderate $\mathrm{AH}$ ) and $<28^{\circ} \mathrm{C}$ (severe AH).$^{3-6}$ In-hospital mortality after severe hypothermia has been reported to be as high as $30 \%$. It is estimated that approximately 1500 people die from hypothermia every year in the USA. ${ }^{14}$ Few previous studies have investigated the incidence and outcome after $\mathrm{AH}$, however, the studies represent heterogenous populations from different climate zones and different time periods. ${ }^{7-10}$ Accordingly, our knowledge of the contemporary incidence, demographics and outcomes after AH remains sparse.

The aim of this study was to investigate the incidence of $\mathrm{AH}$ in a Danish nationwide registry, and the associated outcomes in adult patients.

\section{Geography}

Denmark covers a relatively small area of 4300000 hectares but has a comparatively long coastline. The highest point is $173 \mathrm{~m}$ above sea level. Denmark is located on the 55 th to 57th parallel north in the temperate climate zone. Mean temperatures range from $0^{\circ} \mathrm{C}$ in January and February to $15.7^{\circ} \mathrm{C}$ in August. The population was about 5.8 million 
as of 1 January 2016. About 1.8 million (about $31 \%$ of the population) lived in the capital, Copenhagen.

\section{METHODS}

The present study is a nationwide retrospective cohort study including all adult patients admitted to hospitals in Denmark with a diagnosis of AH from January 1996 to November 2016. The primary outcome was 1-year mortality after diagnosis. We chose a priori to include only those cases with a first-time diagnosis of $\mathrm{AH}$. The rationale behind this decision was to ensure that a patient with multiple hospital admissions for AH only counted once in the analysis.

All Danish residents are given a personal identification number at the time of birth or immigration. This number is used in all contacts with the healthcare system, and it is used as identifier in national registries. Data were extracted from the Danish National Patient Register (NPR) to identify all patients admitted with a discharge diagnosis of $\mathrm{AH}$, defined by the International Classification of Diseases, 10th edition (ICD-10, which has been used in Denmark since 1993) code T689.

Patients were stratified into three groups based on whether $\mathrm{AH}$ was recorded as the only diagnosis (primary $\mathrm{AH}$ ), whether $\mathrm{AH}$ was recorded as the primary diagnosis with other recorded secondary diagnoses $\left(\mathrm{AH}+2^{\circ}\right.$ diagnosis), or whether $\mathrm{AH}$ was recorded as a secondary diagnosis $\left(1^{\circ}\right.$ diagnosis $\left.+\mathrm{AH}\right)$ for a given admission.

The primary diagnosis is defined as the diagnosis primarily causing the need for the admission, while the secondary diagnoses are defined as other conditions that required attention during a given admission. Main treatment categories, such as 'intensive care admission', and 'respirator treatment' were also extracted from the NPR. The AH diagnosis was linked to survival (ie, the primary outcome) using the nationwide Danish Register of Causes of Death.

\section{Patient and public involvement}

Patients or the public were not involved in the design of the present study.

\section{Statistical analyses}

Throughout, categorical variables are presented as counts (\%), normally distributed continuous variables are presented as mean $\pm \mathrm{SD}$ and skewed continuous variables are presented as median (25th percentile to 75th percentile). Normality was assessed visually by $Q Q$ plots prior to analyses. Associations between baseline variables and $\mathrm{AH}$ types were tested by the $\chi^{2}$ test for categorical variables and with the one-way analysis of variance for continuous variable.

To give an overview of common comorbidity, a list of associated ICD-10 diagnoses with a prevalence higher than $1 \%$ in patients with $\mathrm{AH}$ was presented. This overview was stratified by whether $\mathrm{AH}$ was recorded as the primary diagnosis $\left(\mathrm{AH}+2^{\circ}\right.$ diagnosis $)$ or whether $\mathrm{AH}$ was recorded as a secondary diagnosis $\left(1^{\circ}\right.$ diagnosis $\left.+\mathrm{AH}\right)$.

The annual incidence of AH per calendar year was plotted for the total cohort as well as after stratification by $\mathrm{AH}$ type. The mean annual incidence $\pm \mathrm{SD}$ with range was presented. To assess if the incidence of $\mathrm{AH}$ was changing over time, linear models were applied with calendar year being included as a continuous covariate assuming a linear trend. The absolute change in AH incidence per calendar year $\pm \mathrm{SD}$ was presented. The distribution of $\mathrm{AH}$ diagnoses per calendar months were displayed along with mean outside temperatures. The mean annual incidence $\pm \mathrm{SD}$ of $\mathrm{AH}$ after stratification by age group was presented.

We presented crude 1-year mortality rates for the total cohort, as well as after stratification by AH type, by sex and by age group. We presented 1-year mortality after stratification by sex and age group. Differences in mortality between females and males, stratified by age group, were analysed by application of the $\chi^{2}$ test.

For each patient in the cohort, the date of entry (ie, the date of AH diagnosis) as well as the date of death was recorded in the registries. The Kaplan-Meier estimator was applied to visualise time to death within 1 year from admission, stratified by AH type, sex and age group. The log-rank test was applied to assess possible differences between strata.

To analyse time to death between groups, we applied Cox proportional hazard models adjusting for AH type, sex, age at admission and calendar year. We presented HRs with $95 \%$ CIs. A significance level of $<0.05$ was applied throughout. SAS software, V.9.4 (SAS Institute) was used for all statistical analysis.

\section{RESULTS}

Over the inclusion period of almost 22 years, the Danish Health Care System received a total of 5242 adult patients admitted with a diagnosis of AH. A total of 2230 (43\%) had $\mathrm{AH}$ recorded as the final primary diagnosis without any recorded secondary diagnoses (primary AH), 1336 (25\%) had AH recorded as the final primary diagnosis with other recorded secondary diagnoses $\left(\mathrm{AH}+2^{\circ}\right.$ diagnosis), and 1676 (32\%) had $\mathrm{AH}$ recorded as a final secondary diagnosis with another recorded primary diagnosis $\left(1^{\circ}\right.$ diagnosis $\left.+\mathrm{AH}\right)$.

A total of 1981 (38\%) of the patients admitted with AH were women. The mean age was $61 \pm 21$ years. Female sex was slightly less prevalent among patients with primary $\mathrm{AH}$ compared with patients with $\mathrm{AH}+2^{\circ}$ diagnosis and patients with $1^{\circ}$ diagnosis+AH $(35 \%$ vs $39 \%$ vs $40 \%$, $\mathrm{p}<0.001)$. Patients with primary AH were slightly younger compared with patients with $\mathrm{AH}+2^{\circ}$ diagnosis and patients with $1^{\circ}$ diagnosis $+\mathrm{AH}(59 \pm 22$ years vs $62 \pm 20$ years vs $62 \pm 20$ years, $\mathrm{p}<0.001)$.

\section{Comorbidity}

Both $\mathrm{AH}+2^{\circ}$ diagnosis and $1^{\circ}$ diagnosis $+\mathrm{AH}$ were associated with a significant comorbidity burden. A list of 
Table 1 List of associated ICD-10 diagnoses with a prevalence higher than $1 \%$ in patients with accidental hypothermia

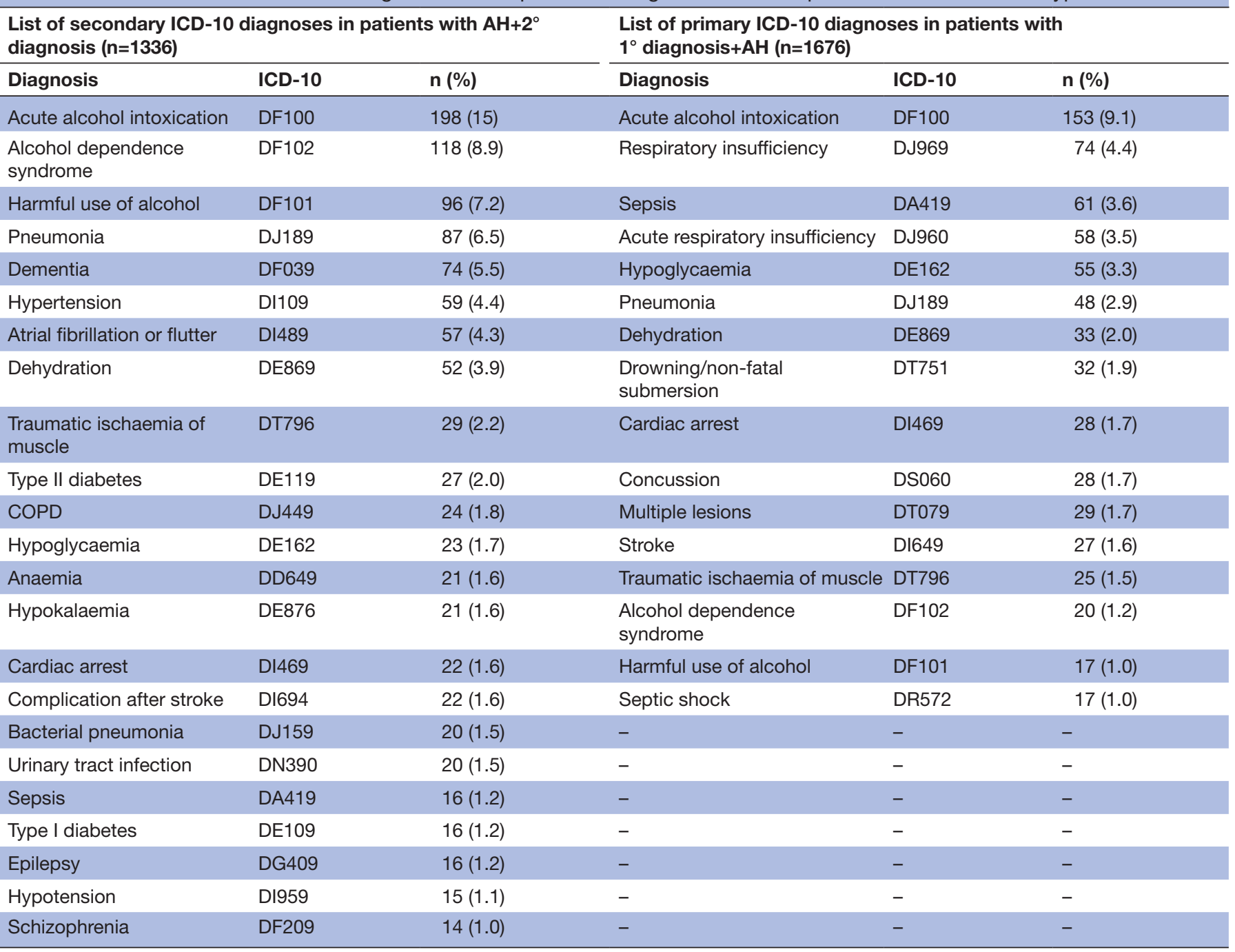

$\mathrm{AH}+2^{\circ}$ diagnosis: $\mathrm{AH}$ recorded as primary diagnosis with one or more recorded secondary diagnoses.

$1^{\circ}$ diagnosis $+\mathrm{AH}$ : $\mathrm{AH}$ recorded as a secondary diagnosis with another recorded primary diagnosis.

associated diagnoses with a proportion higher than $1 \%$ is provided in table 1 . The most frequent diagnosis associated with $\mathrm{AH}$ was alcohol intoxication (table 1 ).

A total of $816(16 \%)$ patients with $\mathrm{AH}$ received care in an intensive care unit (ICU). A total of 305 (5.8\%) were treated with vasopressors and/or inotropic agents, $397(7.6 \%)$ received ventilator treatment, and $479(9.1)$ received dialysis. A total of $21(0.4 \%)$ patients were treated with extracorporeal circulation.

\section{Incidence}

The mean annual incidence of AH was 4.4 \pm 1.2 per 100000 inhabitants with a range from 2.9 to 6.4 per 100000 inhabitants (figure 1). The overall incidence of $\mathrm{AH}$ increased from 2000 to 2016 (absolute increase $0.16 \pm 0.02$ per 100000 inhabitants per calendar year, $\mathrm{p}<0.001$ ).

The annual incidence of AH was $4.3 \pm 1.6$ per 100000 in inhabitants from 18 to 20 years, $2.3 \pm 0.55$ per 100000 in inhabitants from 21 to 40 years, $4.8 \pm 1.1$ per 100000 in inhabitants from 41 to 60 years, $7.2 \pm 2.6$ in inhabitants from 61 to 80 years, and $28 \pm 11$ in inhabitants older than 80 years.

The incidence of AH followed a seasonal trend, with the highest per cent of AH occurring in January $(16 \%)$ and the lowest percent of AH occurring in August (3.0\%, figure 2). Of all AH diagnoses, 29\% were recorded in the Danish capital region inhabited by $31 \%$ of the total Danish population.

\section{Outcome}

Overall mortality within the first 7 days of admission was $11 \%$, increasing to $16 \%$ at 30 days, and $27 \%$ at 1 year. Oneyear mortality was $22 \%$ in patients with primary $\mathrm{AH}, 26 \%$ in patients with $\mathrm{AH}+2^{\circ}$ diagnosis and $35 \%$ in patients with $1^{\circ}$ diagnosis $+\mathrm{AH}(\mathrm{p}<0.001$, figure 3$)$. The higher mortality in patients with comorbidities remained unchanged after adjustment for confounding factors (table 2).

Increasing age was significantly associated with increased 1-year mortality (table 2). One-year mortality increased from $1.6 \%$ in patients between 18 and 20 years to $45 \%$ in patients older than 80 years $(\mathrm{p}<0.001$, table 2$)$. 


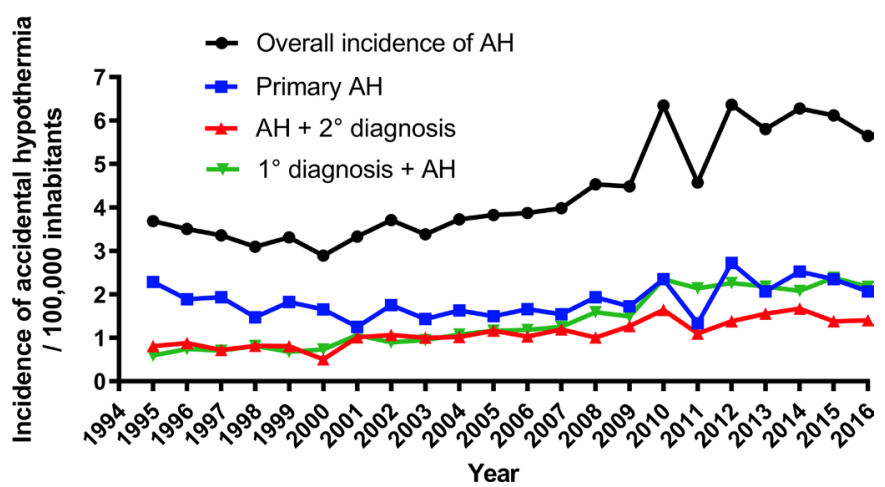

Figure 1 Incidence of accidental hypothermia per 100000 inhabitants per calendar year. Primary $\mathrm{AH}$ : $\mathrm{AH}$ recorded as primary diagnosis without any recorded secondary diagnoses. $\mathrm{AH}+2^{\circ}$ diagnosis: $\mathrm{AH}$ recorded as primary diagnosis with one or more recorded secondary diagnoses. $1^{\circ}$ diagnosis $+\mathrm{AH}: \mathrm{AH}$ recorded as a secondary diagnosis with another recorded primary diagnosis. $\mathrm{AH}$, accidental hypothermia.

One-year mortality was higher in females compared with males (31\% vs $25 \%, \mathrm{p}<0.001$, table 2 ), corresponding to a HR of 1.3 (1.2 to 1.4). In contrast, we found a significantly lower mortality in females older than 80 years compared with men older than 80 years ( $41 \%$ vs $52 \%, \mathrm{p}<0.001$ ), but no significant differences between the sexes in other age groups (table 3). A significantly higher proportion of females were older than 80 years compared with men ( $39 \%$ vs $14 \%, \mathrm{p}<0.001$, table 3 ). The higher overall mortality in women was caused by a higher proportion of women compared with men being older than 80 years. Female sex was associated with a lower mortality compared with male sex after adjustment for confounding factors including age (HR $0.8995 \%$ CI 0.80 to 0.99 , table 2 ).

Calendar year was not associated with outcome in univariate analysis, however, after adjustment, calendar year was associated with slightly decreased mortality with a HR of 0.98 (0.98 to $0.99, \mathrm{p}<0.001$ ) per year (table 2 ).

\section{DISCUSSION}

We chose to stratify patients into three groups (primary $\mathrm{AH}, \mathrm{AH}+2^{\circ}$ diagnosis and $1^{\circ}$ diagnosis $+\mathrm{AH}$ ). The rationale behind this stratification was to distinguish patients

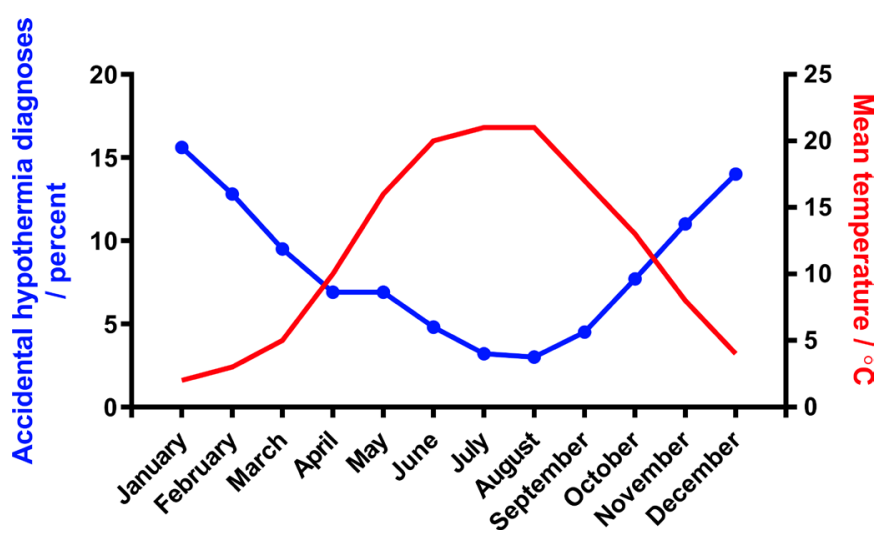

Figure 2 Distribution of accidental hypothermia diagnoses per calendar month.
A

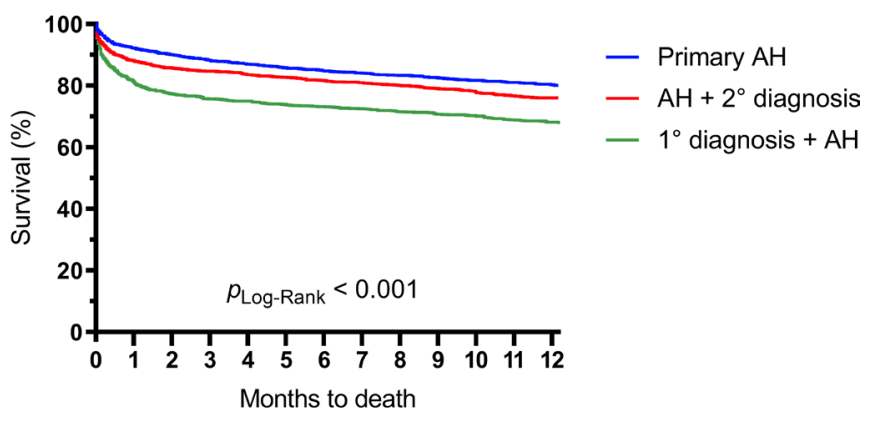

B

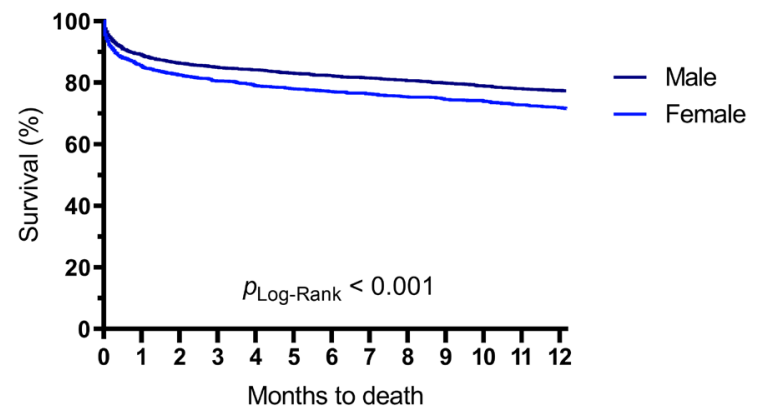

C

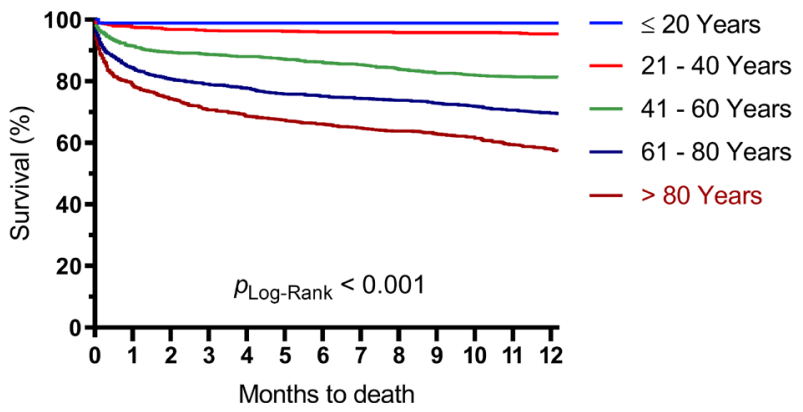

Figure 3 One-year survival in accidental hypothermia patients stratified by $\mathrm{AH}$ type (A), men versus women $(\mathrm{B})$ and by age at admission (C). Primary $\mathrm{AH}$ : $\mathrm{AH}$ recorded as primary diagnosis without any recorded secondary diagnoses. $\mathrm{AH}+2^{\circ}$ diagnosis: $\mathrm{AH}$ recorded as primary diagnosis with one or more recorded secondary diagnoses. $1^{\circ}$ diagnosis $+\mathrm{AH}: \mathrm{AH}$ recorded as a secondary diagnosis with another recorded primary diagnosis. $\mathrm{AH}$, accidental hypothermia.

with isolated $\mathrm{AH}$ and no comorbidity vs patients with comorbidities, when the admitting physician believed that the $\mathrm{AH}$ diagnosis was the primary cause of the admission versus patients with comorbidities, when the admitting physician believed that the AH diagnosis was a secondary cause of admission.

The annual incidence of $\mathrm{AH}$ was 4.4 per 100000 in this study. A study from the Netherlands reported an incidence of AH of 1.1 cases per 100000 per year from 1987 to $1990 .{ }^{8}$ However, in this cohort, trauma was the primary cause of AH suggesting a significantly different population compared with the present study. ${ }^{8}$ A study from four counties with 900000 inhabitants in the northern part of Sweden reported 3.4 cases of AH per 100000 per year in from 2000 to $2007 .{ }^{9}$ In contrast to the present study from a temperate climate zone, the Swedish study was 
Table 2 Associations between covariates and mortality within 1 year

\begin{tabular}{|c|c|c|c|c|c|c|}
\hline & Patients per & Mortality & Univariate models & & Multivariate model ${ }^{\star}$ & \\
\hline & group & n (\%) & HRs $(95 \% \mathrm{Cl})$ & $P$ value & HRs $(95 \% \mathrm{Cl})$ & $P$ value \\
\hline $\mathrm{AH}$ type & & & & & & \\
\hline $\mathrm{AH}+2^{\circ}$ diagnosis & 1336 & $352(26)$ & $1.2(1.1$ to 1.4$)$ & $<0.001$ & 1.2 (1.0 to 1.3$)$ & 0.04 \\
\hline $1^{\circ}$ diagnosis $+\mathrm{AH}$ & 1676 & $582(35)$ & 1.7 (1.5 to 2.0$)$ & $<0.001$ & 1.7 (1.5 to 2.0$)$ & $<0.001$ \\
\hline Male & 3261 & $815(25)$ & 1.3 (1.2 to 1.4$)$ & $<0.001$ & 0.89 (0.80 to 0.99$)$ & 0.04 \\
\hline Age at admission & & & & & & \\
\hline $18-20$ years & 181 & $3(1.7)$ & ref. & & ref. & \\
\hline $21-40$ years & 753 & $43(5.7)$ & 3.5 (1.1 to 11$)$ & 0.03 & 3.4 (1.0 to 11$)$ & 0.04 \\
\hline
\end{tabular}

Results presented as crude mortality rates as well as HRs after application of Cox proportional hazard models, including time to death within 1 year as the outcome variable.

Primary $\mathrm{AH}$ : $\mathrm{AH}$ recorded as primary diagnosis without any recorded secondary diagnoses.

$\mathrm{AH}+2^{\circ}$ diagnosis: $\mathrm{AH}$ recorded as primary diagnosis with one or more recorded secondary diagnoses.

$1^{\circ}$ diagnosis $\mathrm{AH}$ : $\mathrm{AH}$ recorded as a secondary diagnosis with another recorded primary diagnosis.

${ }^{*}$ Adjusted for AH type, sex, age and calendar year.

†Accidental hypothermia (AH).

conducted in a subartic region. However, the Swedish study reported a lower incidence of AH. The Swedish study found an approximate twofold increase in the incidence of AH during the study period. The authors suggest that this may be caused by increased physician awareness and increased reporting. ${ }^{9}$ A study from New Zealand reported an AH incidence of 6.9 per 100000 per year from 1977 to $1986 .^{7}$

There was no clinically significant increase in the incidence of AH during our study period. More males were admitted with AH compared with women. This is consistent with the results of other studies. ${ }^{11-15}$
The incidence of $\mathrm{AH}$ was low during summer and increased during the winter months. The likely explanation is that Denmark has a temperate climate with a cold fall and winter. The increased incidence of $\mathrm{AH}$ during the winter is consistent with findings from other studies of AH in cold climates. ${ }^{9-11} 16-18$

We found an overall 30-day mortality of $16 \%$ and 1-year mortality of $27 \%$. A study from Japan previously reported a high in-hospital mortality of $24 \%$ in a population with AH from 2011 to $2016 .{ }^{10}$ One difference between the two studies was that a significantly higher proportion of patients in the Japanese study were admitted to an ICU

Table 3 Mortality within 1 year stratified by age group and sex

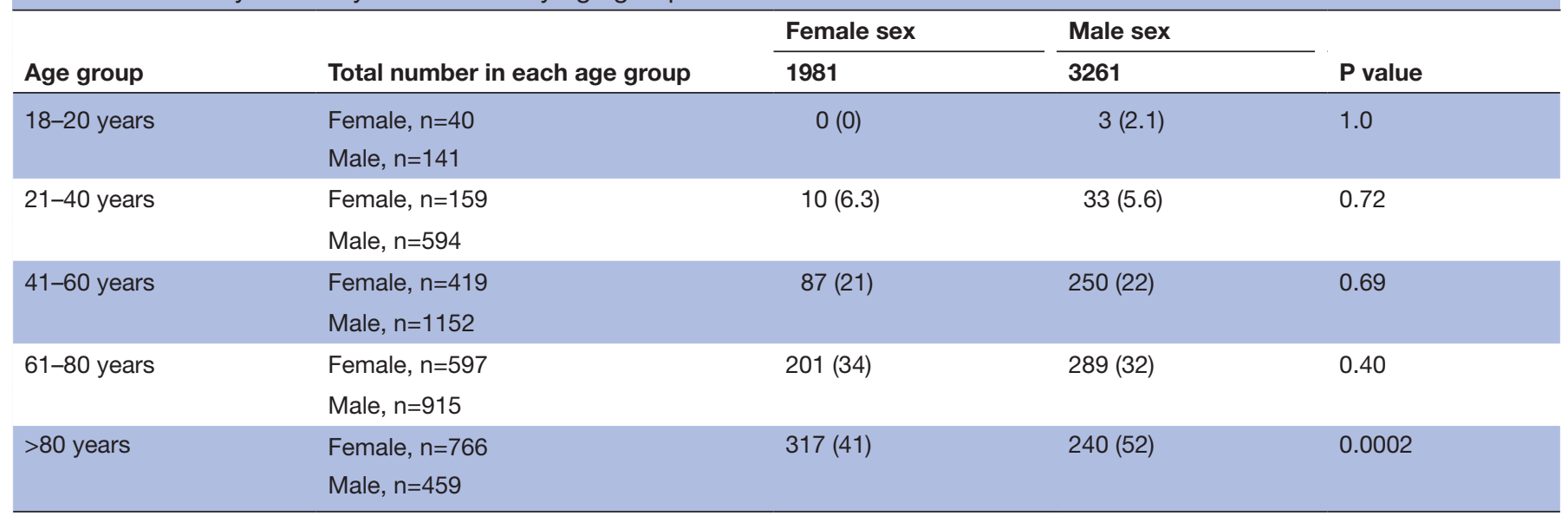

$P$ values for $\chi^{2}$ test (or Fisher's exact test) for difference in mortality between sexes. 
(49\% vs $16 \%)$. The difference in short-term mortality may be explained by different patient characteristics.

In the present study, older age was associated with both increased incidence of $\mathrm{AH}$ and with increased mortality consistent with previously reported data. ${ }^{8} 1920$ The Swedish study also found a higher proportion of older women with $\mathrm{AH} .{ }^{9}$ In our study, women and men had comparable mortality in all age groups with the exception of patients older than 80 years. Women older than 80 years had a significantly lower mortality than men. This may be explained by the long follow-up and the longer life expectancy of women.

We found that the diagnosis of $\mathrm{AH}$ was associated with a burden of comorbidities. Having other recorded diagnoses was associated with a significantly higher mortality compared with having $\mathrm{AH}$ as the only recorded diagnosis (ie, primary $\mathrm{AH}$ ). The association between comorbidity and mortality is consistent with previous studies in $\mathrm{AH}$ populations. $^{1019}$

As with our study, previous studies have also used registry data to address some of the same research questions. The incidence and outcomes of $\mathrm{AH}$ depend on climate, geography and socioeconomic factors.

$\mathrm{AH}$ is a relatively rare diagnosis, and may be overlooked; especially in the case of mild AH presenting with associated diagnoses such as sepsis. Patients with AH constitute a highly heterogenous group depending on the cause of AH. Whether AH or associated diagnoses are the drivers of ensuing morbidity or mortality remains poorly understood. Future studies on AH should ideally be prospective. Eligibility criteria should be based on body temperature measured on admission. Clinical signs on admission should be reported to validate current classification methods of AH stages. ${ }^{6}$ Data collection should include a brief description of the circumstances associated with the event, for example, water accident. Associated diagnoses should be reported, and the treating clinician should ideally record, whether $\mathrm{AH}$ was the driver of any associated diagnoses, whether an associated diagnosis was the driver of $\mathrm{AH}$, or whether $\mathrm{AH}$ and associated diagnoses were considered unrelated. Endpoints should include readmissions after index-admission and all-cause mortality.

\section{Limitations}

A primary limitation of the present study was caused by data originating from national registries. This limited the data granularity to what has been presented in the present paper. While the diagnosis of AH likely has a high specificity, a lower sensitivity may have resulted in underreporting of patients with hypothermia, especially in presence of competing diagnoses. The incidence of secondary AH may be higher than we reported. However, hospitals are reimbursed based on correct reporting of diagnoses, and accordingly, the registry has a high accuracy for most diagnoses. ${ }^{21}$ While diagnoses were classified by treating physicians as primary or secondary, it is unknown to what extent this classification corresponds to primary $\mathrm{AH}$ (AH from isolated cold exposure) and secondary $\mathrm{AH}$ ( $\mathrm{AH}$ in relation to acute or chronic illness). ${ }^{2}$ However, patients whose only diagnosis was AH most likely had primary hypothermia. Excluding additional admissions of patients admitted more than once with a diagnosis of AH might have caused underestimation of the true incidence of $\mathrm{AH}$.

\section{CONCLUSIONS}

The present study investigated the incidence of $\mathrm{AH}$, associated comorbidities, and mortality after AH in Denmark from 1995 to 2016. The diagnosis is associated with a high comorbidity burden and a considerable 1-year mortality. In the high proportion of patients with associated comorbidities, establishing whether $\mathrm{AH}$ or the comorbidities are the drivers of mortality remains difficult. This complicates our understanding of $\mathrm{AH}$ and makes it difficult to find modifiable factors associated with both $\mathrm{AH}$ and outcomes. Future prospective studies are needed elucidate the causal relationship between $\mathrm{AH}$ and associated comorbidities.

Contributors Author MW initiated the project. SW, AFM, JK, CH and MW were involved in planning the study including the statistical analyses. Authors SW and AFM wrote the first draft of the manuscript. SW, AFM, JK, CH and MW were all involved in the production of the final manuscript.

Funding The study was funded by Trygfonden - Accidental Hypothermia (ID: 117579).

Disclaimer The sponsor had no involvement in study design, collection, analysis and interpretation of data, writing of the manuscript or decision to submit the manuscript for publication.

Competing interests None declared.

Patient and public involvement Patients and/or the public were not involved in the design, or conduct, or reporting, or dissemination plans of this research.

Patient consent for publication Not required.

Ethics approval The study was approved by the Danish Patient Safety Authority (Institutional review board, ref. no. 3-3013-1906/1/) and was conducted consistent with the Declaration of Helsinki. As we conducted a national retrospective study over a time period of 21 years, the Danish Patient Safety Authority approved the study without need for obtaining consent from each individual.

Provenance and peer review Not commissioned; externally peer reviewed.

Data availability statement Data may be obtained from a third party and are not publicly available. Data were extracted from national Danish registries. Accordingly, assess to data can be obtained by application to the relevant Danish authorities.

Open access This is an open access article distributed in accordance with the Creative Commons Attribution Non Commercial (CC BY-NC 4.0) license, which permits others to distribute, remix, adapt, build upon this work non-commercially, and license their derivative works on different terms, provided the original work is properly cited, appropriate credit is given, any changes made indicated, and the use is non-commercial. See: http://creativecommons.org/licenses/by-nc/4.0/.

\section{ORCID iD}

Sebastian Wiberg http://orcid.org/0000-0002-7062-7189

\section{REFERENCES}

1 van der Ploeg G-J, Goslings JC, Walpoth BH, et al. Accidental hypothermia: rewarming treatments, complications and outcomes from one University medical centre. Resuscitation 2010;81:1550-5.

2 Brown DJA, Brugger $\mathrm{H}$, Boyd J, et al. Accidental hypothermia. $N$ Engl J Med 2012;367:1930-8. 
3 Durrer B, Brugger $\mathrm{H}$, Syme D, et al. The medical on-site treatment of hypothermia: ICAR-MEDCOM recommendation. High Alt Med Biol 2003;4:99-103.

4 Truhlár A, Deakin CD, Soar J, et al. European resuscitation Council guidelines for resuscitation 2015: section 4. cardiac arrest in special circumstances. Resuscitation 2015;95:148-201. doi:10.1016/j. resuscitation.2015.07.017

5 Pasquier M, Zurron N, Weith B, et al. Deep accidental hypothermia with core temperature below $24^{\circ} \mathrm{C}$ presenting with vital signs. High Alt Med Biol 2014;15:58-63.

6 Musi ME, Sheets A, Zafren K, et al. Clinical staging of accidental hypothermia: the revised Swiss system: recommendation of the International Commission for mountain emergency medicine (ICAR MedCom). Resuscitation 2021;162:182-7.

7 Taylor NAS, Griffiths RF, Cotter JD. Epidemiology of hypothermia: fatalities and hospitalisations in New Zealand. Aust N Z J Med 1994;24:705-10.

8 Bierens JJ, Uitslager R, Swenne-van Ingen MM, et al. Accidental hypothermia: incidence, risk factors and clinical course of patients admitted to hospital. Eur J Emerg Med 1995;2:38-46.

9 Brändström H, Johansson G, Giesbrecht GG, et al. Accidental cold-related injury leading to hospitalization in northern Sweden: an eight-year retrospective analysis. Scand J Trauma Resusc Emerg Med 2014;22:6.

10 Matsuyama T, Morita S, Ehara N, et al. Characteristics and outcomes of accidental hypothermia in Japan: the J-Point registry. Emerg Med $J$ 2018;35:emermed-2017-207238-66.

11 Baumgartner EA, Belson M, Rubin C, et al. Hypothermia and other cold-related morbidity emergency department visits: United States, 1995-2004. Wilderness Environ Med 2008;19:233-6.

12 Rango N. Exposure-related hypothermia mortality in the United States, 1970-79. Am J Public Health 1984;74:1159-60.
13 Hsieh T-M, Kuo P-J, Hsu S-Y, et al. Effect of hypothermia in the emergency department on the outcome of trauma patients: a cross-sectional analysis. Int J Environ Res Public Health 2018;15. doi:10.3390/ijerph15081769. [Epub ahead of print: 17 Aug 2018].

14 Svendsen Øyvind Sverre, Grong K, Andersen KS, et al. Outcome after rewarming from accidental hypothermia by use of extracorporeal circulation. Ann Thorac Surg 2017;103:920-5.

15 Debaty G, Moustapha I, Bouzat P, et al. Outcome after severe accidental hypothermia in the French Alps: a 10-year review. Resuscitation 2015;93:118-23.

16 Zhang P, Wiens K, Wang R, et al. Cold weather conditions and risk of hypothermia among people experiencing homelessness: implications for prevention strategies. Int J Environ Res Public Health 2019;16. doi:10.3390/ijerph16183259. [Epub ahead of print: 05 Sep 2019].

17 Danzl DF, Pozos RS, Auerbach PS, et al. Multicenter hypothermia survey. Ann Emerg Med 1987;16:1042-55.

18 The Eurowinter Group. Cold exposure and winter mortality from ischaemic heart disease, cerebrovascular disease, respiratory disease, and all causes in warm and cold regions of Europe. The Eurowinter group. Lancet 1997;349:1341-6.

19 Okada Y, Matsuyama T, Morita S, et al. Prognostic factors for patients with accidental hypothermia: a multi-institutional retrospective cohort study. Am J Emerg Med 2019;37:565-70.

20 Morita S, Matsuyama T, Ehara N, et al. Prevalence and outcomes of accidental hypothermia among elderly patients in Japan: data from the J-Point registry. Geriatr Gerontol Int 2018;18:1427-32.

21 Thygesen SK, Christiansen CF, Christensen S, et al. The predictive value of ICD-10 diagnostic coding used to assess Charlson comorbidity index conditions in the population-based Danish national Registry of patients. BMC Med Res Methodol 2011;11:83. 